\title{
The sleep-dream cycle and convulsion threshold
}

ERNEST HARTMANN, JANE MARCUS, and ANDREW LEINOFF, Tufts University School of Medicine, Boston State Hospital, Boston, Mass. 02124

Electroconvulsive seizure threshold in the mouse was found to be lowered by reserpine and also by D-deprivation (REM-deprivation). D-deprivation plus reserpine produced a greater lowering than either alone. High positive correlations between the two effects across animals (mice more "sensitive" to reserpine were more sensitive to D-deprivation) suggests that the same or closely related mechanisms are involved.

The aim of this study was to investigate the effect on the electroshock convulsion threshold (CT) of a number of conditions and agents which produce altered sleep patterns. Cohen \& Dement (1965) have shown in the rat that four days of D-deprivation-preventing the animal from having D-periods (REM-periods)-produced a small but significant reduction in convulsion threshold. This study was indended to replicate these results in another species and then to study conditions other than D-deprivation which we have shown to affect D-pressure. D-pressure refers to the tendency to have D-periods, apparently augmented after D-deprivation. Dpressure, need for D, REM tendency, or some similar concept is used in almost every sleep laboratory in spite of our ignorance of the basic neural mechanisms involved. Increased D-pressure is usually measured by increased D-time or D-time per cent, decreased D-latency, or increased REM-density-i.e., number of eye movements per unit of time during D-periods. D-pressure appears to be reduced by certain antidepressant drugs (Hartmann, 1968a) and by EST (Cohen \& Dement, 1966). In our experience it is increased by reserpine which has been shown by others to reduce CT (Bianchi \& Camillo, 1956; Chen \& Bonner, 1956). Thus we have suggested that depression is closely related to D-pressure (Hartmann, 1968a, b).

We hypothesized that D-deprivation and reserpine, agents which increase D-pressure, would reduce CT in mice and would do so by the same mechanism, so that animals more susceptible to the effect of one agent would also be more susceptible to the effects of the other. Specific hypotheses were as follows: (1) D-deprivation will reduce (T: (2) reserpine will reduce $C T$; (3) reserpine plus D-deprivation will produce a greater reduction in CT than either the deprivation or reserpine alone; or (4) there will be a positive correlation across animals between the effects of reserpine and the effects of D-deprivation.

\section{METHOD}

A total of 60 young adult male Webster Swiss mice were employed. Groups of 10 to 20 mice were run in each experiment. Each animal was used as its own control, i.e., each had usually at least three baseline convulsion-threshold terminations at least $48 \mathrm{~h}$ apart and at least one experimental session for whatever condition was being studied. Convulsion threshold for each animal was then compared under baseline and experimental conditions.

Separate experiments indicated that placebo injections had no effect on CT, and individual vs group housing had no effect on $\mathrm{CT}$.

CT was determined by the method of Schwartzbaum et al (1958) with electrodes attached to the ears of the mice, and electrical stimulation at 60 cycles per second and lasting $0.2 \mathrm{sec}$. Stimuli were applied by specially built constant current stimulator and monitored at all times on a dual beam oscilloscope.

D-deprivation was carried out by the technique involving a mouse on a small wooden island surrounded by water. No further studies were performed in an animal for two weeks after a D-deprivation procedure or for one month after reserpine administration.

\section{RESULTS}

Baseline CT by this technique was found to be $16.4 \mathrm{~mA}$ with a standard deviation of $2.0 \mathrm{~mA}$. Table 1 summarizes the results of the experiment. D-deprivation for either 48 or $72 \mathrm{~h}$ resulted in a decreased CT while the control situation, similar to the experimental one except that the islands were large enough so that no D-deprivation should occur, produced no change in CT. Reserpine, $5 \mathrm{mg} / \mathrm{kg}$, produced a reduced CT at 6 and $25 \mathrm{~h}$ after administration. The combined effect of $72 \mathrm{~h}$ of D-deprivation and reserpine $6 \mathrm{~h}$ before CT determination was a reduction on CT greater than that produced by either condition alone.

Since a number of deaths resulted from the CT determina-

Table 1

The Effects of Reserpine and of D-Deprivation on Convulsion Threshold in Mice

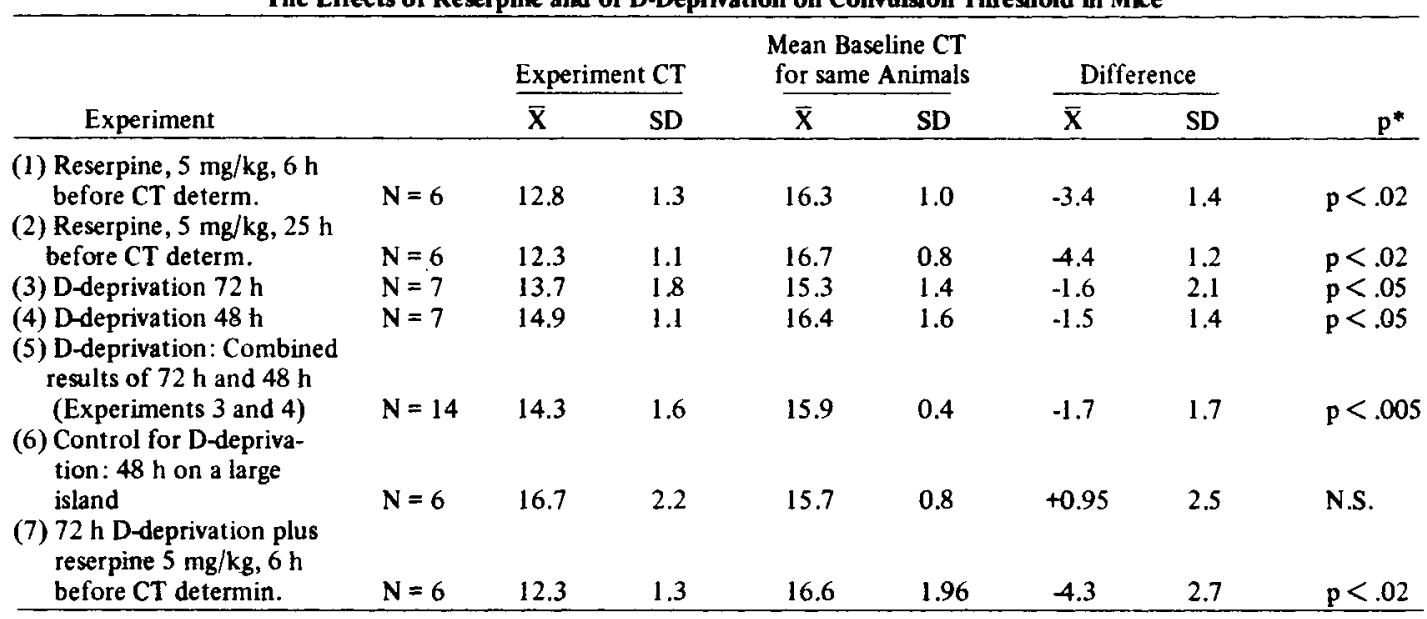

- Determined by the Walsh test for related samples (12). 
tions, it was not possible to use the same groups of animals in all experiments. However, from the above experiments and several additional ones it was possible to obtain 10 animals who had each experienced at least two baseline CT determinations, one CT determination after $72 \mathrm{~h}$ of D-deprivation, and one CT determination 6 or $25 \mathrm{~h}$ after reserpine. Animals were ranked for change from baseline after D-deprivation and change from baseline after reserpine, and a rank correlation coefficient determined. Results were: $r_{8}=+.89, p<.001$.

\section{DISCUSSION}

Hypotheses $1-4$ are supported by the results. Both D-deprivation and reserpine appear to reduce $C T$ in mice and their combined effect is greater than the effect of either agent alone. Furthermore the high correlation $(+.89)$ found between the two effects suggests that they act on the same mechanism or at least on two closely related mechanisms.

It has previously been suggested that levels of brain monoamines (Chen et al, 1968) or specifically of brain dopamine (Heymans et al, 1964) may be related to CT. Higher amine levels are associated with higher CT. It is also certain that monoamine metabolism is related to D-pressure. We have noted that a number of conditions and agents thought to produce lower levels of "functionally available Norepinephrine" are associated with increased D-pressure and vice versa (Hartmann, in press). Thus it is possible that the effects of D-deprivation as well as of reserpine on CT are related to the effect on monoamine metabolism and perhaps specifically to reduced NE levels. The converse of this relationship also holds: the "antidepressant" agents which tend to increase NE levels and decrease D-pressure, such as repeated electroconvulsions, MAO inhibitors, and amitriptyline have been shown to raise the convulsive threshold (Chen et al, 1968; Tainter et al, 1943).

\section{REFERENCES}

BIANCHI, C. Anticonvulsant action of some antiepileptic drugs in mice pretreated with Rauwolfia Alkaloids. British Journal of Pharmacology, $1956,11,141-146$.

CHEN, G., \& BOHNER, B. A study of the neuropharmacologic properties of certain convulsants, anticonvulsants, and reserpine. Journal of Pharmacology \& Experimental Therapeutics. 1956, 117, 142-147.

CHEN, G., ENSOR, C., \& BOHNER, B. Studies of drug effects on electrically induced extensor seizures and clinical implications. Archives Internationales de Pharmacodynamie et de Therapie, 1968 , 172, 183-218.

COHEN, H., \& DEMENT, W. Sleep: Changes in threshold to electroconvulsive shock in rats after deprivation of paradoxical phase. Science, 1965, 150, 1318-1319.

COHEN, H., \& DEMENT, W. Sleep: Suppression of rapid eye movement phase in the cat after electroconvulsive shock. Science, 1966, 154, 396-398.

HARTMANN, E. Antidepressants and the need for D: (and suggested mechanism maintaining depression.) Report to the Association for the Psychophysiological Study of Sleep, April, 1967. Abstract: Psychophysiology. 1968a, 4, 390-391.

HARTMANN, E. On the pharmacology of dreaming sleep (the D-state). Journal of Nervous \& Mental Disease, 1968b, 146, 165-173.

HARTMANN, E. Sleep and the monoamines. Report to the Association for the Psychophysiological Study of Sleep, Denver, March, 1968. Abstract: Psychophysiology, in press.

HEYMANS, C., De SCHAEPDRY VER, A., DELAUNOIS, A., \& PIETTE, $Y$. Brain amines and electroshock convulsive threshold. Indian Journal of Physiological Pharmacology, 1964, 3, 113-116.

SCHWARTZBAUM, J., HUNT, E., DAVIES, B., KIMELDORF, D. The effect of whole body $X$ irradiation on the electroconvulsive threshold in the rat. Journal of Comparative \& Physiological Psychology, 1958, $51,181-184$

SIEGEL, S. Nonparametric statistics for the behavioral sciences. New York: McGraw-Hill, 1956.

TAINTER, M., et al. Influence of various drugs on the threshold for electrical convulsions. Journal of Pharmacology \& Experimental Therapeutics, 1943, 78, 42-54. 